\title{
Managing the first period at home with a newborn: a grounded theory study of mothers' experiences
}

\author{
Esther Hjälmhult PhD, RN, RPHN (Associate Professor) ${ }^{1}$ and Kirsten Lomborg PhD, MScN, RN (Associate \\ Professor) $)^{1,2}$ \\ ${ }^{1}$ Faculty of Health and Social Sciences, Bergen University College, Bergen, Norway and ${ }^{2}$ Department of Nursing Science, Institute of Public \\ Health, Aarhus University, Aarhus, Denmark
}

Scand J Caring Sci; 2012

\section{Managing the first period at home with a newborn: a grounded theory study of mothers' experiences}

Aim: The article aims to present a theoretical account of mothers' first period at home with their newborn in Norway.

Background: Mothers' well-being affects their babies and is therefore an important priority for public health. Early discharge after childbirth is common in many countries. In Norway, this has been practised for 5-10 years but without any distinct agreement between maternity hospitals and the community health services and without documented follow-up care. Knowledge is lacking in how mothers deal with the first period at home with the baby.

Method: Seven focus group discussions were conducted with 26 mothers who had babies 1.5-3 months old. The grounded theory method was used to gather and analyse data. Results: The mothers were strongly concerned about preserving their control and integrity in the new situation. This main concern was resolved by the strategy of priori- tizing newborn care. The strategy encompassed a process of developing competence as a mother, changing focus in relationships, stretching to the critical level and seeking recognition. These parallel processes were inter-related, sometimes mutually supportive and sometimes conflicting. When conflicts occurred, prioritizing newborn care guided mothers in finding solutions. Breaches of the implied conditions in health care tended to increase mothers' level of strain and uncertainty and to influence their efficacy in breastfeeding the baby.

Conclusion: Being a mother to a newborn is a dynamic and extensive process. Succeeding in breastfeeding seems especially sensitive and essential in motherhood. The idea that giving birth is a simple and normal situation may obscure the importance of seamless health care and the need for professional support and information.

Keywords: motherhood, newborn, integrity, breastfeeding, home visit, grounded theory.

Submitted 31 May 2011, Accepted 5 January 2012

\section{Background}

Mothers are often vulnerable in the first period after childbirth (1-4). A newborn baby, especially the first one, is a great adjustment in the parents' life, and preventive health care is designed in various ways in both industrialized and developing countries to meet the needs of parents and children (5). In Norway, a child health promotion programme covers all children from birth to 5 years (6). The public health nurse (PHN) has a key role and often first meets the clients at a home visit to the family with a

\section{Correspondence to:}

Esther Hjälmhult, Associate professor, Faculty of Health and Social Sciences, Bergen University College, Møllendalsveien 6, N-5009

Bergen, Norway.

E-mail: ehj@hib.no newborn. Norway's regulations stipulate that this be offered within 2 weeks after birth. This policy was appropriate when the mother and child stayed at the hospital for 5 days or more, breastfeeding was established, the baby had stopped losing weight and diverse types of screening were carried out (7-9).

Today, however, there is a significant gap in the continuum of patient care offered by the public health care services in the postnatal period. A report from the Norwegian Board of Health Supervision (NBHS) (10) demonstrates great variation in the content and the quality of care from the time of discharge for maternity units until well-baby clinics provide follow-up for the family and the baby. According to the report, no binding agreements have been made between the different health services since early discharge (1-3 days after birth) was implemented at many hospitals in Norway during the past 5-10 years. Paradoxically, some municipalities have even reduced home visits (KOSTRA 2009 - Report System). Taken 
together, distinct intersectoral coordination of public health care and follow-up documentation of the effects of the new initiatives is lacking.

Globally, breastfeeding of newborns varies (11). The prevalence is traditionally very high in Norway. Among newborns, $99 \%$ are exclusively breastfed, $82 \%$ at 4 weeks, about $50 \%$ at 4 months and $80 \%$ are partly breastfed at 6 months (12). Promoting breastfeeding is important at public health, and knowledge, skills and support are essential to sustaining a high frequency (13-16).

Many women have increased vulnerability following delivery (17). The incidence of postpartum depression has been $10-15 \%$ in the past 10 years $(18-20)$. New risk factors include lack of postnatal care. Lack of sleep is a risk factor for depression $(21,22)$ for some mothers, and breastfeeding problems may contribute to postpartum depression $(23,24)$.

Maternity wards and health promotion must expand in accordance with changes in society and meet families' needs $(10,25,26)$. The perspectives of the people involved are important in obtaining knowledge and improving the quality of public health care practice. Thus, learning how current public health practice is effective in meeting the needs of families would be of interest. We initiated this study to explore how mothers experience the first period at home with the baby and how they manage their new life.

\section{Methods}

For data collection and analysis, we chose a grounded theory design, which aims to generate theory rather than mere description $(27,28)$. In accordance with Morgan's (29) focus group method, seven focus group discussions were conducted with 26 mothers with babies.

\section{Data collection and setting}

The mothers were recruited in collaboration with the leaders of public health services and their PHNs, who distributed letters with information to mothers visiting the well-baby clinics in different parts of a major provincial city. The criteria were being 18 years or older, primiparous or multiparous, with or without experience of home visiting, speaking Norwegian and having a baby 1.5-3 months old. Ten participants were first-time mothers, and 16 mothers had 2-4 children. None were single mothers; the variation was otherwise rich, with different experiences of 'natural' childbirth, some acute and planned caesarean, twins, mature babies and some moderately premature ones. The mothers were 20-40 years old, and the mothers had diverse demographic characteristics. They had the hospital's early discharge of 1-2 days, except for seven with complications and one who chose another hospital.
In accordance with Norwegian law, approval by the Western Norway Regional Medical and Health Research Ethics Committee was not relevant. Ethical principles were ensured. The participants were informed orally and in writing about the purpose of the study. Confidentiality issues and the right to withdraw from the interview were explained. We informed the Norwegian Social Science Data Services.

With a semistructured interview guide, we conducted seven focus group discussions from December 2008 to June 2009 at some well-baby clinics. As recommended by Kvale \& Brinkman (30), we tried to create a relaxed environment to provide an atmosphere of trust so that the participants would feel free to share their experiences. Morgan's (29) idea about the interaction in group discussion as the source of data and the researcher's active role in listening and in creating the group discussion guided the sessions. In accordance with the focus group literature (29, 31 ), we started the focus groups with small talk and gave information about the purpose and framework of the group discussions. The mother and baby were presented briefly before the first question: 'How has it been to live at home with a newborn baby?' Each group responded eagerly, demonstrating that the mothers had much to discuss in a mutually supportive atmosphere. The project leader moderated the discussions, taking responsibility to facilitate the mothers' interaction and to balance the social dynamics between them without controlling. A co-moderator assisted with refreshments and noted special statements or nonverbal expressions. Each session lasted about 1.5 hours and was audio-recorded and transcribed.

\section{Data analysis}

Data analysis comprised two simultaneous activities: coding data and writing memos. We consecutively transcribed and inductively coded and analysed the first five focus group sessions by generating hypotheses from the data about what was happening in the area studied. Each interview was coded before the next interview by the first author. The analysis started with open coding using a constant comparison of incidents exploring similarities and differences. We identified the mothers' main concern - the first period at home with a newborn. We used the next two focus group sessions to ensure demographic variety in the data material and to enrich the emerging codes and hypotheses. The study progressed to identify the core category that could capture the patterns of behaviour by which the mothers resolve their main concern including during which conditions. Subsequently, we grouped the codes into subcategories, thereby translating the descriptive concepts. Next, we continued theoretical coding, which relates the concepts of the theory to each other clearly and distinctly at a more abstract level $(27,28)$ until we found theoretical saturation (Table 1). 
Table 1 Phases in the analysis

\begin{tabular}{|c|c|c|}
\hline Phases & Purpose & Results \\
\hline \multicolumn{3}{|c|}{ 1. Substantive coding } \\
\hline (a) Open coding & $\begin{array}{l}\text { Generate substantive } \\
\text { codes and categories } \\
\text { and their dimensions }\end{array}$ & $\begin{array}{l}\text { Downgrading needs, } \\
\text { seeking respect and } \\
\text { understanding, and } \\
\text { comparing different } \\
\text { babies }\end{array}$ \\
\hline $\begin{array}{l}\text { (b) Selective } \\
\text { coding }\end{array}$ & $\begin{array}{l}\text { Select codes related to } \\
\text { the core category }\end{array}$ & $\begin{array}{l}\text { Only relevant codes: } \\
\text { Downgrading needs, } \\
\text { seeking respect and } \\
\text { understanding }\end{array}$ \\
\hline $\begin{array}{l}\text { 2. Theoretical } \\
\text { coding }\end{array}$ & $\begin{array}{l}\text { Formulate hypotheses } \\
\text { that describe } \\
\text { relationship between } \\
\text { the substantive } \\
\text { categories }\end{array}$ & $\begin{array}{l}\text { The more the } \\
\text { downgrading needs, } \\
\text { the more the seeking } \\
\text { respect }\end{array}$ \\
\hline
\end{tabular}

\section{Results}

The mothers were primarily concerned about 'preserving control and integrity in their new situation', and they found this very challenging. They strived to resolve this concern by 'prioritizing newborn care'. This strategy encompassed four subcategories: developing competence in motherhood, changing focus in relationships, stretching to the critical level and seeking recognition (Fig. 1).

\section{Conditions of prioritizing newborn care}

The characteristic conditions of prioritizing newborn care were experiencing being vulnerable and receptive to stress. Especially for the first-time mothers, who often did not know what to expect and what to do, the experiences were insecurity and anxiety in understanding and handling the baby the first days after discharge. After some weeks, most

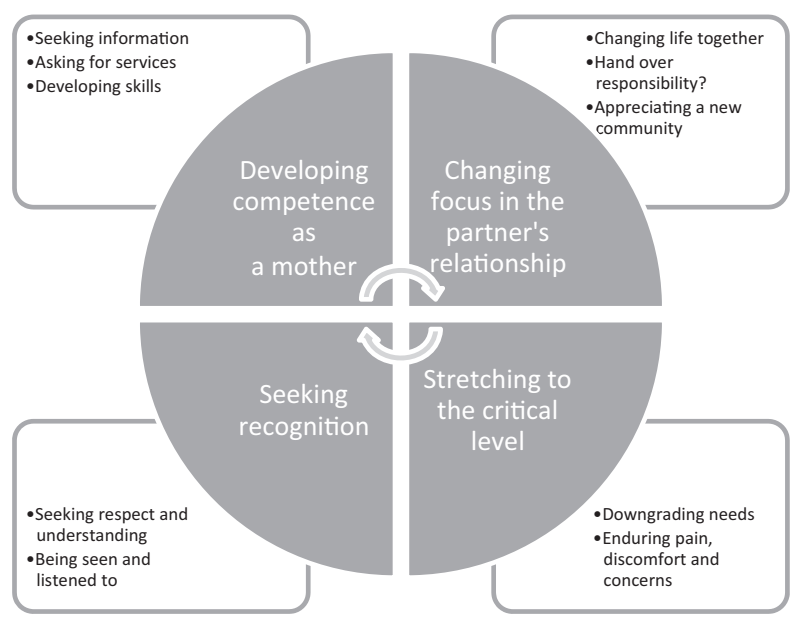

Figure 1 Prioritizing newborn care. of the mothers felt more relieved and happy, but still tired and 'full of hormones', as they said.

Please remember that we are in a very vulnerable situation; even the tiniest thing may cause stress. As far as hormones are concerned, it doesn't take much before you break down completely and everything you have is tears, and everything just floats. (FG6) Conditions were related to the baby's and the mother's well-being, her success in breastfeeding, her opportunities to sleep and receive support, changes in her body and dealing with siblings and everyday duties. Mothers explained the differences between being a first-time mother and a mother with experience. They knew each delivery and child was different, and the mothers mentioned altered needs. Breastfeeding the first child could be okay, but now it was a problem: for instance, sore nipples or the baby sucked too weakly and failed to gain weight.

A few mothers reluctantly had to supplement with breast-milk substitute. They did not like that situation, as they wanted to solely breastfeed. 'Nor did I expect to be so touchy about it. I thought I was going to lose my milk, but then it improved and I felt on top again.' Working up sufficient milk for the baby was therefore a triumph, and the mother's self-efficacy increased. In this process, the support from the PHN and husband was welcomed. The PHN could be good in theory and support verbally but perhaps not to practically demonstrate how the baby should 'hook on'.

\section{Developing competence as a mother}

The mothers sought information about what is normal in childbirth, motherhood, the baby, relationship with the husband, etc. and compared themselves to these norms. The new mothers wanted to know how to comfort a crying baby, how to hold a baby and whom to contact for any acute situations. The novice did not discern the quality of the baby's crying; the experienced mother usually did this rather quickly. The information sought included relevant telephone numbers and addresses if needed. The Internet was more important during pregnancy.

The mothers also asked for services. They were engaged in developing their role as mother and reported typically that the PHN contacted them by telephone and asked whether they wanted a home visit or to visit her at the well-baby clinic. Some, however, did not get the choice of a home visit.

It was convenient for me not to have to go outside; I was sore and had to lie down often (to breastfeed), so it was very convenient that she could make a home visit, especially since then 'Dad' would be home and get information, too. (FG6)

There was more time to just talk, more relaxing than having to go to the clinic. Having to go out is just fussier. (FG2) 
The participants experiencing home visits were satisfied with meeting the PHN in their home. They talked about the childbirth, postnatal period, lactation, sore nipples, taking care of the baby, siblings, relationship and other questions on developing skills.

I got home visits on both occasions. It was very convenient - very, very convenient. I'm more relaxed about it now - it wasn't impeccable, I didn't offer freshly baked buns or coffee. I bet everything looked a complete mess. But both times the public health nurse focused very much on me. The experience was very positive for me, I felt. (FG5)

Some mothers expressed ambivalence about having a public employee in their home. They disliked control and wanted the encounter to take place at the clinic. 'It is voluntary, yes, but a PHN may see a lot of things, because you can see much in a home.' Another point was that one family did not get the offer of a home visit for the first baby but for the next one. A mother then could wonder why.

I was a bit surprised. 'What do you want', I thought ... In the beginning when you get home, everything seems kind of topsy-turvy. She probably heard the panic in my voice. (FG5)

The offers from the well-baby clinics seemed to be unclear for new mothers. What can a family expect from this service? Some mothers with older children had gradually discovered how flexible and accessible the PHN was and recommended that the well-baby clinics market their services better. The participants even emphasized that they wanted continuity and to meet the same PHN for their child or children.

Breastfeeding was extremely important and seemed to represent success in motherhood. Some mothers had good experiences, but many had a history of hard work, including sore and painful breasts and anxiety about managing breastfeeding and about whether the child was satisfied. 'The breasts were stone hard and incredibly painful! They couldn't be sucked for they were as hard as stone. Fortunately, a friend had a pump I could borrow.' They were astonished at the magnificent breasts in the beginning but also wondering how to get the baby 'hooked on'.

I have been struggling with breastfeeding. During the first month, he only gained 20 grams. I floundered a lot; I started stressing when my spouse went back to work. At that time, too, apparently because [the baby] didn't get enough nutrition, he got restive. Perhaps he, too, noticed that I was stressed and, as a result, didn't manage to suck properly. Then I became very sore and started to bleed. (FG7)

She continued, obviously happy and proud:

We did go to the well-baby clinic, and I was advised to complement with a bit of breast-milk substitute. Put simply, he got the substitute so that he could regain his appetite. At that time, he got $20-30 \mathrm{ml}$ after each meal. Now things are looking very good. Last time I weighed him he had gained 400 grams in 9 days! He is solely breastfed now, but he has to be fed from both breasts. (FG7)

In this way, a mother demonstrated not giving up but developing competence in breastfeeding. Other skills were 'everything' about having a baby, their clothes and hygienic habits and needs. Another issue we identified was how mothers with more than one child had to organize the day in a new way, finding time for various activities and needs and sibling rivalry.

\section{Changing focus in the partner's relationship}

A second strategy in prioritizing newborn care was mothers' focus in the relationship with their husbands, which had changed and was sometimes encumbered by difficulty in transferring responsibility to him. The mother concentrated her attention on the baby, which the father seemed to accept according to the mother. They were changing their life together, at least with their first baby.

Having a child changes everyday life completely; the focus is completely different, and there is a great difference between being girlfriend and boyfriend and being parents. Not in a negative way, they are just two different worlds. (FG3)

The couple experienced a new dimension and they appreciated a new community: 'Our relationship is strengthened - we have something new and to love jointly.' Another aspect was the time they had together: the opportunities for just the two of them were reduced.

I feel I don't have time for him anymore. In the evenings it's like this: 'Oh, we haven't even hugged.' The day has gone by. None of us even thought about hugging. All our attention is on [the baby] ... it's not what we're used to. And, in addition, when we don't manage to share meals, it's almost as if it's not until the evening comes that one discovers that there actually are two of us here. (FG7)

Even nights were different: the couple might sleep in separate rooms, sometimes in consideration of the father and other times, when the father snored, of the mother. A comment was that when the father sleeps, he really sleeps. He did not hear the baby during the night or that the mother was awake and did a great job with the baby. Another comment was the opposite, it makes no sense for two people to awaken; he had his work too during the day. Some families have a deal to share the work at night on weekends.

Mothers said that being able to deal with the work at home and perhaps handing over responsibility was important for the relationship. Many participants said that the father took care of the mother and had looked forward to 10 days off work after childbirth. Mothers felt that they must have control of the baby and instructed their husbands as to what they could or not could do. They knew 
that they should let him do it his way, but this could be hard to practise. Mothers found it easier to hand over responsibility to the father for child number two or three, because the father also had experience and was more skilled. Some mothers admitted, however, that they wanted to take care of the baby themselves, talking about 'mothers' heart' and even that the father was a bit helpless and uncomfortable with the baby.

\section{Stretching to the critical level}

This strategy showed how the mothers tended to downgrade their needs and to endure pain, discomfort and concerns, and they strived to fulfil expectations. During the first month, especially first-time mothers could overlook eating and taking care of themselves. The baby took all their attention and time.

Our own eating is downplayed. We forget to feed ourselves. Oh, that's why I'm dizzy, of course. Everything but the child seems peripheral. It feels as if all I do is breastfeed. (FG2)

In that respect, with our first child, I was greedy. At least initially, I could go like that the entire day. My main preoccupation was that she should get fed often. I completely forgot about myself. I even lost my hair. This time it's different; I have some kind of calm now. (FG6) Another issue was the lack of sleep. The mother was sensitive to the baby, awoke to various sounds and crying for food. The baby may not have had a good rhythm, cried often and the older child woke up at 06:00. Days and nights were strenuous.

Even if mothers breastfed the babies, they mentioned painful and sore breasts when lactating started. They got information from the PHN, books and friends about good positions during breastfeeding, various utensils and so on. The problem often started just 2-5 days after childbirth.

My nipples became so sore they almost split in two. Every time I breastfed was as painful as giving birth 10 times. 'This is going to be the last time she gets breast; I can't stand any more of this.' Still, every time I ended up thinking: 'I will try one more time.' (FG1)

This mother requested - and got - professional help and gradually succeeded in enjoying breastfeeding. The focus groups discussed the pressure to succeed in everything and not to mention difficulties. When something unexpected happened to them, they wondered whether they were normal and alone with the problems.

Pieces of my nipples actually fell off. I had never heard about anything like that happening to anybody - is it taboo to talk about that sort of thing? I've never before heard something like that happening, neither the bleeding nor the fact that it is possible actually to lose pieces of ... your nipple. (FG7)

Even toilet problems could be hindering in daily life the first time at home - with painfulness and concern about normality after laceration and sewing. They could not talk about how they worried, cried and wondered. Perhaps, a friend was entrusted. If the baby had trouble with sucking, some mothers pumped the breast-milk and gave it to the child. This was time-consuming but demonstrated patience for the baby.

I pump manually; thus, my forearm is incredibly strong. The pumping itself isn't all that bad; it's the sterilizing that is time-consuming. It's no problem when you get used to it, though. I think we adjust ourselves to these kinds of things when we become parents. I used to be more impatient. But you have to do what you have to do. (FG5)

They did not seem to have a limit for stretching themselves. A question was when a mother forgot to take care of herself.

These first three months have been a constant blur. I do things over and over and over. Breastfeed, change napkins, sleep. Even if I tried, I couldn't manage to do anything besides this. There's a lot of trial and error. It's like being in a vacuum; I never manage to get on with anything else. (FG3)

Mothers discussed depression after earlier childbirth. They did not know what it was but had cried a lot and did not tell anybody. They tried to do everything perfectly and were afraid that the feelings were abnormal. The mothers mentioned internal and external expectations.

They could feel well immediately after the birth and arrival at home and open up for family and friends to congratulate them. Nevertheless, this could be too much. Several mothers said they did not manage to prepare or cook dinner at home with the first baby. Time flew. Their husbands had expectations: "But you are at home all day?" I think it myself too - I ought to have time and opportunities.' This seemed to be easier with the next child. Then, however, parents may have a new challenge: managing the first child could be one of the most difficult things. The older children have their needs and care and did not like too much attention focused on the baby.

Mothers seldom showed their frustration or anger and blew up, but it happened sometimes. The sensitive period after birth influenced the family, and mothers blamed hormones.

After birth, I was so full of hormones. ... my mood kept changing between rage, weeping and joy. There were incredible hormonal fluctuations. If I didn't find the car keys that I had mislaid, I could scold my husband in rage. (FG4)

They wanted to have reasonable control during the day and present a good image to the surroundings. This could be difficult. After short nights and bothersome mornings with the children, for instance, a mother could arrive at 11:00 at kindergarten with a sibling. Comments such as 'Our core time is 09:00 to 14:00' got the mother to blow up at the staff. Afterwards, she felt guilty. She did not want to 
give them a bad impression and came on time the following days but tired. Mothers tried to live up to expectations in motherhood and had comments about being a 'good girl'. They stretched to the critical level, but quite a few said they fell short. 'I don't feel good about myself, really, I constantly feel that I'm not good enough, that I don't have what it takes and ...' They appreciated health professionals who supported and took care of the family.

\section{Seeking recognition}

Seeking recognition in the process of prioritizing newborn care was vital. They sought affirmation that they did the 'right things'. Mothers sought respect and understanding, but several had started coming home with a sense of not being treated as an individual at the hospital. They did not get the support or practical help from staff they had wanted; they were confused and insecure and wanted to go home. However, a few first-time mothers with complications who had to stay at hospital more than 48 hours were happy to get professional support for breastfeeding and handling the baby and could not understand how mothers could manage all this (alone) at home.

The study showed that mothers needed to be seen and listened to and appreciated encouragement for their activities as a mother. The PHNs' home visits were welcomed, and mothers in focus groups expressed being satisfied with the service from well-baby clinics. If they worried about something, they appreciated being taken seriously.

The public health nurses understand why we ask these questions; they don't seem to find them stupid but take them seriously. The people at the well-baby clinic convey confidence ... and they are accessible; we always feel we can ask. (FG1)

They strongly disliked being stressed. The first week at home was stressing returning to hospital for screening, perhaps every day if the baby had jaundice. The father provided support, but everyone did not have 10 days of paid leave. Later, mothers even expressed a need for variation to manage the day and their new life. A mere hour at sometimes without the baby was wonderful and made a big difference. Otherwise, in seeking recognition, several mothers looked forward to meet like-minded mothers in small groups at well-baby clinics.

\section{Consequences of prioritizing newborn care}

The processes of (a) developing competence, (b) changing focus, (c) stretching to the critical level and (d) seeking recognition were interwoven, sometimes mutually supportive and sometimes conflicting. When conflicts occurred, prioritizing newborn care guided women in finding solutions. The breach of implied conditions in health care tended to increase mothers' strain and uncertainty and to influence their efficacy in breastfeeding.
When developing competence or stretching to the critical level, the mothers needed feedback and sought recognition that they were good mothers and handled the situation normally. Lack of positive feedback strained them. Experience of recognition and of support in developing skills influences the degree of stretching to the critical level. Changing focus in relationships was interrelated with the degree to which the husband accepted and understood her choice to give priority to newborn care by prioritizing newborn care.

\section{Discussion}

This grounded theory study delineates the complexity of mothers' first period at home with a newborn: how they try to preserve control and integrity in their new life by 'prioritizing newborn care'.

\section{Strengths and limitations}

Assessing the quality of grounded theories requires analysing the criteria of fit, work, relevance and modifiability $(27,32)$. Our data came from Norway, from a hospital that has a relatively new clinical practice of early discharge after childbirth but without seamless services for the families with newborns. Studying single mothers and non-native speaking mothers would probably provide further details. The strength of the study, however, is the inclusion of firsttime and multiparous mothers with varying cases and demographics. We therefore believe this grounded theory of prioritizing newborn care fits well the mothers' experience. Further, we believe the theory is relevant for PHN and 'works' to explain the complexity of the mothers' experiences.

\section{Preserving control and integrity in the new situation}

Being recognized and treated as an individual was important for mothers in developing competence to manage the situation. In their efforts to become secure and get an overview for preserving control and integrity, they were engaged in normality concerning themselves, the babies and the new situation. Many of them did not know what was normal and disliked asking, perhaps because they would be revealed as abnormal. Although giving birth is normal, being especially vulnerable and even worn out postpartum is also normal $(2,33,34)$. This study showed that practical training, information and support for mothers just after giving birth seem to be minimal, as others have documented $(17,35,36)$. The stress of returning to the outpatient clinic for diverse types of screening did not facilitate preserving control for a weary mother.

Thus, the mothers in this study experienced not being prepared in the first period after coming home. Some studies of early discharge have not reported negative 
consequences (37-39). The reason could be more seamless care from the hospital to the community with prepared staff and women or that the mothers had a choice of early discharge (40). Women's individual needs rather than routine should guide health services and distinguish the roles of various health professionals, as described previously (41-43). Caring, flexibility and predictability should therefore be discussed at the units providing maternal, newborn and child care and facilitate prioritizing newborn care. Further, providing sufficient information efficiently from the hospital to well-baby clinics should not be a problem in an electronic world, enabling PHN to offer a home visit the first days at home to inform and comfort the parents. Home visits contribute to building relationships and normalizing the new situation, and especially common problems with breastfeeding and taking care of the baby are reported earlier (44-47).

\section{Succeeding in motherhood}

When mothers in this study downgraded their needs and endured pain, discomfort and concerns, this was part of prioritizing newborn care. Lack of sleep was a significant concern, and mothers could overlook eating. Mothers were engaged with the baby 24 hours a day, partly relieved by the father. Other studies emphasized this period by reporting that $40 \%$ of mothers had days in the first month when they never got dressed (17), and $60 \%$ of mothers with a baby at 2 months of age had serious sleep deprivation and even found that trouble with sleep was a risk factor for postnatal depression $(21,22,48)$. Further, breastfeeding problems could contribute to postnatal depression $(23,49)$. These conditions confirmed the women's vulnerability postpartum.

A symbol for success in motherhood seemed to be breastfeeding, which correlates with Larsen et al. (50), who discuss breastfeeding and motherhood as inseparable phenomena. Mothers in our study talked about fighting to succeed, about sustained hardship and about beaming and pride when the baby's weight increased. They tended to breastfeed despite problems. This phenomenon correlates with Tufte (51), who found that $88 \%$ of the women in their study experienced breastfeeding problems during the period of lactation, with debut concentrated on the first days after giving birth. This attitude confirmed a strong breastfeeding culture in accordance with other studies (52, 53) and reflecting 'prioritizing newborn care'. Mental factors, breastfeeding problems and supplementation during the first week are associated with early weaning (15,
54). In this perspective, mothers need to be listened to and meet high quality and competence in counselling through empowering behaviour, a sense of integrity and autonomy and encourage resting instead of receiving guests.

\section{Giving priority to newborn care}

The study showed that mothers' feeling of normality is important, and they wanted to present an image without problems but still openly discussed sensitivity and being vulnerable in this period, with increased workload, 'baby blues', lack of sleep and breastfeeding. The women experienced intensive responsibility, and the father's support and understanding were valuable for the mother's wellbeing and self-efficacy, which correlates with research from maternity wards $(35,36,55)$. In the intensive process of mothering, however, they kept an eye on their husbands' competencies to ensure that he deserved the responsibility for newborn care. Preparing and encouraging a new father, including at the home visits and wellbaby clinic, are important in improving the father's competence and parents' satisfaction.

\section{Conclusion}

Becoming a mother is a vulnerable period and a radical process. Prioritizing newborn care accounts for how mothers manage their concern for preserving control and integrity in their new situation and encompass processes of developing competence in motherhood, changing focus in relationships, stretching to the critical level and seeking recognition. Succeeding in breastfeeding seems especially sensitive and essential in motherhood, and to succeed in breastfeeding as well as taking care of the baby, mothers will ignore basic needs to eat and sleep, and suppress painful and sore breasts and toilet problems. Although giving birth is normal, being vulnerable and worn out postpartum is also normal. This study showed that practical training, information and support for mothers just after giving birth seem to be minimal and that the stress of returning to the outpatient clinic for diverse types of screening may not facilitate preserving control for a weary mother. The idea that giving birth is a simple and normal situation may obscure the importance of seamless health care and need for professional support, information and care. Increased knowledge may improve the ability of the people involved to facilitate, preventing mothers from stretching their critical level too far.

\section{References}

1 Cox JL, Holden J. Perinatal Mental Health: A Guide to the Edinburgh Post- natal Depression Scale (EPDS). 2003, Gaskell, London.

2 Eberhard-Gran M, Slinning K. Nedstemhet og depresjon $i$ forbindelse med fodsel [Mood Disorders and Depression in Connection with Childbirth]. 2007, Norwegian Institute of Public Health, Oslo. 
3 Forster DA, McLachlan HL, Ryan J, Yelland J, Gold L, Rayner S. The early postnatal period: exploring women's views, expectations and experiences of care using focus groups in Victoria, Australia. BMC Pregnancy Childbirth 2008; 8: 27.

4 Glavin K, Ellefsen B, Erdal B. Norwegian public health nurses' experience using a screening protocol for postpartum depression. Public Health Nurs 2010; 27: 2255-62.

5 Hall D, Williams J, Elliman D. Child Surveillance Handbook, 3rd edn. 2009, Radcliffe Publishing, Oxford.

6 Norwegian Directorate of Health. Kommunenes helsefremmende og forebyggende arbeid $i$ helsestasjons- og skolehelsetjenesten [The Municipalities' Work for Health Promotion and Disease Prevention in Well-Baby Clinics and School Health Services]. 2004, Norwegian Directorate of Health, Oslo. (Veileder til forskrift av 3. April 2003 nr. 450).

7 Moritz ML, Manole MD, Bogen DL, Ayus JC. Breastfeeding-associated hypernatremina: are we missing the diagnosis? Pediatrics 2005; 116: 343-7.

8 Reilev M, Børch K, Pryds OA. Hypernatriæmisk dehydrering hos nyfødte - hvorfor stigende incidens? [Hypernatriemic dehydration among newborn children - why is the incidence increasing?] Ugeskr Laeger 2007; 169: 1227-31.

9 Tjora E, Reigstad H. [A 6-day-old girl with weight loss]. Tidsskr Nor Legeforen 2009; 129: 868-9.

10 Norwegian Board of Health Supervision. Korleis tek fødeinstitusjonen og kommunen vare på behova til barselkvinna og det nyfødde barnet $i$ barseltida? [How Do Maternity Units and Health Centres Meet the Needs of Mothers and Babies in the Post-Natal Period?]. 2011, Norwegian Board of Health Supervision, Oslo. (Report No 3/2011; short version in English).

11 World Health Organization. Infant and Young Child Feeding. Model Chapter for Textbooks for Medical Students and Allied Health Professionals. 2009, World Health Organization, Geneva.

12 Norwegian Directorate of Health, University of Oslo and Norwegian Food Safety Authority. Spedkost - 6 måneder: landsomfattende kostholdsundersøkelse blant 6 måneder gamle barn [Norwegian Infant Nutrition Survey Among Six-Month-
Old Infants, 2006-2007]. 2008, Norwegian Directorate of Health, Oslo.

13 Norwegian Resource Centre for Breastfeeding. Annual Report 2004. 2005, Norwegian Resource Centre for Breastfeeding, Oslo.

14 Chung M, Ip S, Yu V, Raman G, Trikalinos T, DeVine D. Intervention in primary care to promote breastfeeding: a systematic review. Ann Intern Med 2008; 149: 565-82.

15 Häggkvist AP, Brantsæeter AL, Grjiboviski AM, Helsing E, Meltzer HM, Haugen M. Prevalence of breastfeeding in the Norwegian Mother and Child Cohort Study and health service-related correlates of cessation of full breast-feeding. Public Health Nutr 2010; 13: 2076-86.

16 Bäckström CA, Wahn EI, Ekström AC. Two sides of breastfeeding support: experiences of women and midwifes. Int Breastfeed J 2010; 5: 20.

17 Fishbein EG, Burggraf E. Early postpartum discharge: how are mothers managing? J Obstet Gynecol Neonatal Nurs 1998; 27: 142-8.

18 Eberhard-Gran M, Tams K, Opjordsmoen S. Depression in pregnancy and after delivery - a repeated measurement study. $J$ Psychosom Obstet Gynaecol 2004; 25: 15-21.

19 Hallbreich U, Karkun S. Cross-cultural and social diversity of prevalence of postpartum depression and depressive symptoms. J Affect Disord 2006; 91: 97-111.

20 Glavin K, Smith L, Sørum R. Prevalence of postpartum depression in two municipalities in Norway. Scand $J$ Caring Sci 2009; 23: 705-10.

21 Dørheim S, Bondevik GT, EberhardGran M, Bjorvatn B. Sleep and depression in postpartum women: a population-based study. Sleep 2009; 32: 847-55.

22 Dørheim S, Bondevik GT, EberhardGran M, Bjorvatn B. Subjective and objective sleep among depressed and non-depressed postnatal women. Acta Psychiatr Scand 2009; 119: 128-36.

23 Eberhard-Gran M, Eskild A, Tams K, Samuelsen SO, Opjordsmoen S. Depression in postpartum and nonpostpartum women: prevalence and risk factors. Acta Psychiatr Scand 2002; 106: 426-33.

24 New Hampshire Breastfeeding Task Force. A Breastfeeding-Friendly Ap- proach to Depression in New Mothers. 2009, New Hampshire Breastfeeding Task Force, Concord, NH.

25 Ministry of Health and Care Services. En gledelig begivenhet: om en sammenhengende svangerskaps-, fodsels- og barselomsorg [A Happy Event: On Coherent Pregnancy, Birth and Postnatal Care]. 2009, Ministry of Health and Care Services, Oslo. (Report No. 12 (20082009) to the Storting; short version in English).

26 Norwegian Institute of Public Health. Folkehelserapport 2010: helsetilstanden $i$ Norge [Public Health Report 2010: The State of Health in Norway]. 2010, Norwegian Institute of Public Health, Oslo.

27 Glaser BG. Theoretical Sensitivity: Advances in the Methodology of Grounded Theory. 1978, Sociology Press, Mill Valley, CA.

28 Glaser BG. The Grounded Theory Perspective III: Theoretical Coding. 2005, Sociology Press, Mill Valley, CA.

29 Morgan DL. Focus groups. Annu Rev Sociol 1996; 2: 129-52.

30 Kvale S, Brinkman S. Learning the Craft of Qualitative Research Interviewing. 2009, Sage Publications, London.

31 Kitzinger J. Introducing focus groups. Br Med J 1995; 311: 299-302.

32 Lomborg K, Kirkevold M. Truth and validity in grounded theory - a reconsidered realist interpretation of the criteria fit, work, relevance and modifiability. Nurs Philos 2003; 4: 189-200.

33 Nysæther H, Bærug A, Nylander G, Klepp KI. [Rooming-in in the maternity ward - are mothers satisfied?]. Tidsskr Nor Legeforen 2002; 122: 12069.

34 Kronborg H, Væth M. The influence of psychosocial factors on the duration of breastfeeding. Scand J Caring Sci 2004; 32: 201-16.

35 Rudman A, Waldenström U. Critical views on postpartum care expressed by new mothers. BMC Health Serv Res 2007; 5: 178.

36 Persson E, Fridlund B, Kvist L, Dykes AK. Mothers' sense of security in the first postnatal week: interview study. J Adv Nurs 2011; 67: 105-16.

37 Waldenström U, Sundelin C, Lindamark G. Early and late discharge after hospital birth: breastfeeding. Acta Paediatr Scand 1987; 76: 727-32. 
38 Arborelius E, Lindell D. Psychological aspects of early and late discharge after hospital delivery. An interview study of 44 families. Scand J Soc Med 1989; 17: 103-7.

39 Persson E, Dyke AK. Parents' experience of early discharge from hospital after birth in Sweden. Midwifery 2002; 18: 53-60.

40 Löf M, Svalenius EC, Persson EK. Factors that influence first-time mothers' choice and experience of early discharge. Scand J Caring Sci 2006; 2: $323-30$

41 MacArthur C. What does postnatal care do for women's health? Lancet 1999; 353: 343-4.

42 McLachlain HL, Gold L, Forster DA, Yelland J, Rayner J, Rayner S. Women's views of postnatal care in the context of the increasing pressure on postnatal beds in Australia. Women Birth 2009; 22: 128-33.

43 Yelland J, Krastev A, Brown J. Enhancing early postnatal care: findings from a major reform of maternity care in three Australian hospitals. Midwifery 2009; 25: 392-402.
44 Vehviläinen-Julkunen K. The function of home visits in maternal and child welfare evaluated by service providers and users. J Adv Nurs 1994; 20: 672-8.

45 Jansson AK, Pettersson K, Udèn G. Nurses' first encounters with parents of new-born children - public health nurses' views of a good meeting. $J$ Clin Nurs 2001; 10: 140-51.

46 Jansson AK, Sivberg B, Wilde Larsson B, Udèn G. First-time mothers' satisfaction with early encounters with the nurse in child health care: home visit or visit to the clinic? Acta Paediatr 2002; 91: 571-7.

47 Christ M, Sawyer T, Muench D, Huillet A. Comparison of home and clinic well-baby visit in a military population. Mil Med 2007; 172: 5159.

48 Ross LE, Murray BJ, Steiner MJ. Sleep and perinatal mood disorders: a critical review. J Psychiatry Neurosci 2005; 30: 247-56.

49 Edhborg M, Friedberg M, Lund W, Widstöm AM. Struggling with life: narratives from women with signs of postpartum depression. Scand J Public Health 2005; 33: 261-7.

50 Larsen JS, Hall EOC, Aagaard H. Shattering expectations: when mothers' confidence in breastfeeding is undermined - a metasynthesis. Scand J Caring Sci 2008; 22: 653-61.

51 Tufte E. Breastfeeding Problems Among Norwegian Women. Thesis. 2005, Nordic School of Public Health, Göteborg.

52 Grassley J, Nelms T. Understanding maternal breastfeeding confidence: a Gadamerian hermeneutic analysis of women's stories. Health Care Women Int 2008; 23: 841-62.

53 Kronborg H, Væeth M, Olsen J, Harder I. Health visitors and breastfeeding support: influence of knowledge and self-efficacy. Eur J Public Health 2008; 18: 283-8.

54 O’Brien M, Buickstra E, Hegney E. The influence of psychological factors on breastfeeding duration. $J$ Adv Nurs 2008; 6: 397-408.

55 Melender HL. What constitutes a good childbirth? A qualitative study of pregnant Finnish women. J Midwifery Womens Health 2006; 51: 331-9. 